\title{
3D VIRTUAL RECONSTRUCTION OF THE MIDDLE STOA IN THE ATHENS ANCIENT AGORA
}

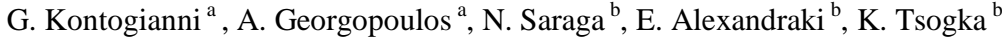 \\ ${ }^{a}$ Laboratory of Photogrammetry, School of Rural \& Surveying Eng., \\ National Technical University of Athens \\ ${ }^{\mathrm{b}}$ A' Ephorate of Prehistoric and Classical Antiquities, Ancient Agora of Athens \\ Ministry of Educational and Religious Affairs, Culture and Tourism
}

KEY WORDS: 3D reconstruction, Multisource data, Verisimilitude of data

\begin{abstract}
:
Reconstruction is an action that re-builds a ruin or a non-existing structure trying to reproduce its form and shape at a given moment of its past. Reconstruction of Cultural Heritage monuments used to be common practice during the $19^{\text {th }}$ and $20^{\text {th }}$ centuries. However, contemporary ways of thinking and approaching the issue of reviving the past have introduced a lot of scepticism as far as reconstructions are concerned. An attractive alternative is virtual reconstruction, which does not involve any intervention to the existing relics, while it offers all advantages to the curator. In this paper the virtual reconstruction of a non-existing building of the Athenian Agora is described, presented and visualized. All data collected were evaluated and used appropriately for the final product. It is evident that, on one hand, the data collected do not all belong to the target period and, on the other, not all the data necessary to built up the model are available today. Therefore, one needs to carefully select the data corresponding to the period of study and complete them with suitable hypotheses. It is imperative that both tasks must be done in collaboration of the archaeologists and architects responsible for the monument. In this context a hierarchy of the data was developed, based on their reliability as far as their "correctness" is concerned. The data were categorized for their reliability after careful evaluation. The accuracy of the data depends on the source; hence the data which originate from a drawing or from one study of the 3D reconstructed monument are considered more accurate than data which come from a source referring to architectural elements of other monuments or written reports of travelers. Sometimes the data appear in more than one source, in this case they must be checked for their reliability. In cases of remaining artifacts that could be found in the museum and belonged to the building a different approach was followed. They were used to produce 3D models and these were later attached to the final 3D model. From the final virtual reconstruction a short video has also been produced for the better visualization of the result.
\end{abstract}

\section{INTRODUCTION}

The Ancient Agora is today one of the most important archaeological sites in Athens and is situated at the northern foot of the Acropolis hill. It was a large open space to the south of Eridanos River and served as the political, administrative, philosophical, educational, social and economical centre of the town of Athens for many centuries.

The Middle Stoa is an elongated building $147 \mathrm{~m}$ by $17.5 \mathrm{~m}$, which ran east-west across the old square, dividing it into two unequal halves (Figure 1). At just under 150 meters long, it is the largest building in the Agora, with Doric colonnades at both north and south as well as an Ionic colonnade down the middle. Traces of a narrow parapet that ran between some of the columns can be made out on individual drums. The original steps and three columns remain in situ at its eastern end; to the west, only the heavy foundations of reddish conglomerate survive. Except for its size the Middle Stoa is a relatively modest building, made of limestone, with a terracotta roof. It was built between ca. 180 and 140 B.C. and it was continuously used even during of the Roman era (www.agathe.gr). Foreign architects are believed to have been responsible for its construction; hence it presents particular design and construction elements not usual for that time in the area. Today the foundations of this majestic building and some individual parts of it are visible in the site.
There were many attempts to study the initial appearance of the Middle Stoa and today a lot of related material is available, although sometimes controversial. Drawings, descriptions and artists' impressions, among others, try to revive the building with a multitude of approaches and results.

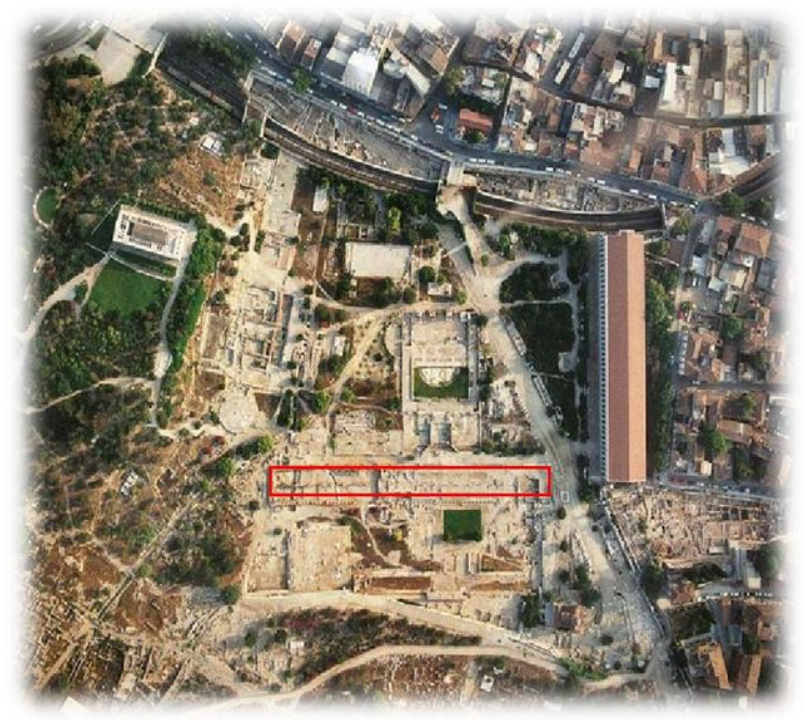

Figure 1: Position of the Middle Stoa in the Athenian Agora 


\section{VIRTUAL RECONSTRUCTION}

The term reconstruction implies the re-building of a monument to its state at a particular time moment of its past life, chosen for the representation. The term has similar meaning with the terms anastylosis and restoration, with the difference that the anastylosis is expected to use the authentic material, while for the restoration new material may be used, but both are implemented up to the point where assumptions about the original form of the monument are required. Digital technologies have enabled the virtual reconstruction. This term implies that the representation takes place in a computer three dimensional space, which is usually called virtual environment and the final product is usually called a 3D virtual model (Matini et al., 2009).

There are many kinds of virtual reconstruction, mainly focussing on the verisimilitude of data used. Usually the different data are illustrated with different colours, every colour representing different data source. Another way of representation is that the object parts are illustrated with different transparency level according to the reliability of original source. In this case important role plays the data date, their accuracy and their likelihood. The differentiation may also represent the knowledge about the original construction material.

Symmetry, which is a very important element in architecture, may also be represented and interpreted with the virtual reconstruction, while building the geometry of the architectural elements, like windows, doors, arcs etc. Another important element is the representation of the construction method of each element or section of the monument. Hence, the process of virtual reconstruction must be done very carefully in order to create the virtual model correctly both geometrically and photorealistically (De Fuentes et al. 2010, Gkintzou et al. 2012, Valle Melon et al. 2005)

Virtual reconstruction supports many other disciplines involved in cultural heritage. It helps architects in their work for monuments especially in cases of restoration, anastylosis etc. Archaeologists and Conservationists have a very good tool for their studies. Many applications can be generated from a virtual reconstruction like virtual video tours of the monument for educational and other purposes for use by schools, museums and other organizations, for incorporation into a geographical information system (GIS) for archaeological sites, for the design of virtual museums and the creation of numerous applications for mobile devices (e.g. mobile phones, tablets etc).

\section{DATA AVAILABLE}

For the reconstruction of the Middle Stoa many types of data were available. They were carefully studied and evaluated and as a result of this thorough research it was decided which ones were going to be used and how. These data, used for the virtual reconstruction are:

- A complete reconstruction study by Architect John Travlos (1963), where he had also drafted many missing parts of the Middle Stoa.

- A reconstruction study by the American School of Classical Studies in Athens, where parts at the small side of the Stoa were designed Mc Camp II 2004).

- Two drawings which illustrate the existing situation of the foundations of the building. The first one illustrates the situation at the southwest side and the other depicts the krepis at the northeast side, which still survives in a very good condition.

- Drawings illustrating particular architectural elements of the Middle Stoa. These drawings concern the roof tiles of the monument and the type of the triglyphs. All these drawings come from the archive of the American School of Classical Studies in Athens (www.agathe.gr).

- A 3D reconstruction of the foundations at the south western part of the building, which was made using contemporary surveying and photogrammetric techniques (Karageorgou et al. 2008).

In addition to the above valuable information from many publications was also used. These sources include:

- John Travlos' "Pictorial Dictionary of Athens" (1971), which includes drawing from a reconstruction study from some parts of the monument.

- Muller-Wiener's "Architecture in Ancient Greece" (1995), where valuable information was found about the decoration of the molding (geison).

For the rendering phase of the monument drawings illustrating particular parts of the monument with their colour were used (Figures 2 and 3). These images were published in the web site of the American School of Classical Studies in Athens.

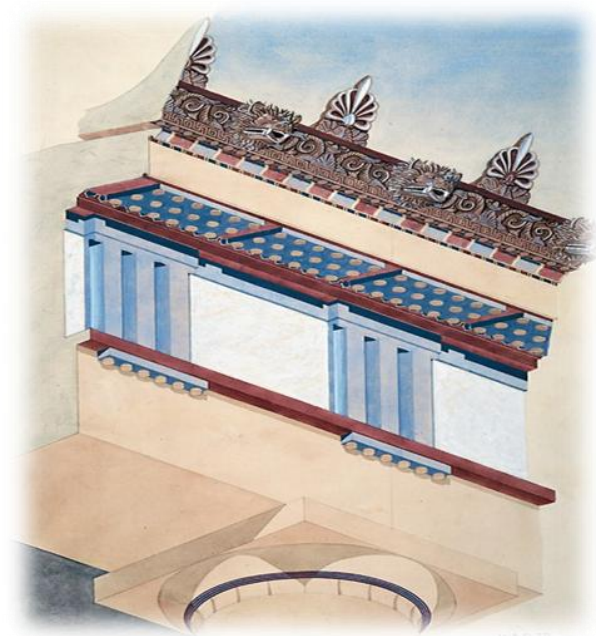

Figure 2: Drawing of part of the reconstructed building

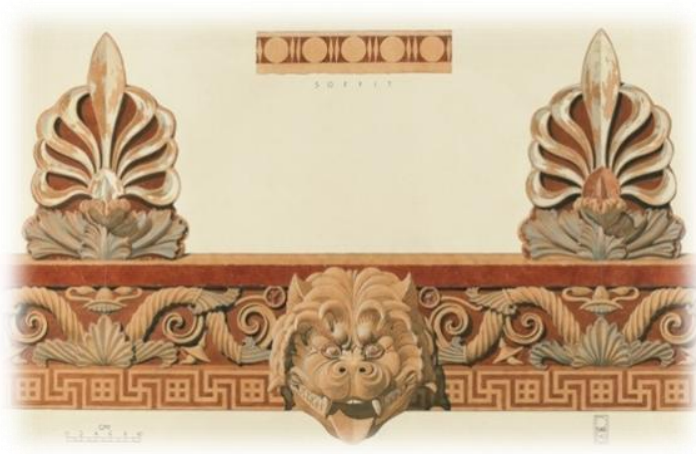

Figure 3: Drawing of Middle Stoa's sima

In cases where the information was not leading to firm conclusions as to the original form of the monument parts, the advice, comments and suggestions of specialised scientists, responsible for the Athenian Agora, proved to be valuable. All 
the available data were evaluated and classified according to their verisimilitude in terms of accuracy and likelihood (Table $1)$.

\begin{tabular}{|c|c|c|c|}
\hline \multirow{2}{*}{ Source } & \multicolumn{3}{|c|}{ Characteristics } \\
\cline { 2 - 4 } & Year & $\begin{array}{c}\text { Order in } \\
\text { accuracy }\end{array}$ & $\begin{array}{c}\text { Order in } \\
\text { likelihood }\end{array}$ \\
\hline 3D Model & 2010,2012 & 1 & 1 \\
\hline $\begin{array}{c}\text { Architectural } \\
\text { plans of Stoa }\end{array}$ & $1963,1965,1966$ & 2 & 2 \\
\hline $\begin{array}{c}\text { Other } \\
\text { architecture } \\
\text { plans }\end{array}$ & Varies & 3 & 3 \\
\hline Images & Varies & 5 & 5 \\
\hline Literature & Varies & 4 & 4 \\
\hline Assumptions & - & 6 & 6 \\
\hline
\end{tabular}

Table1: Data evaluation

In Table 1 data originating from the 3D model (Karageorgou et al. 2008) were considered as highly accurate compared to the rest. Architectural plans of the Middle Stoa are quite accurate, because they illustrate an important part of the reconstructed building and were compiled after very careful studies. The assumptions are the less accurate piece of data. They were used only in the case where there were no other data available to represent the object correctly.

\section{RECONSTRUCTION OF THE MIDDLE STOA}

The virtual reconstruction of the Middle Stoa was performed in Autodesk 3ds Max using all available data mentioned previously. Within the software the basic steps of the reconstruction workflow are the following:

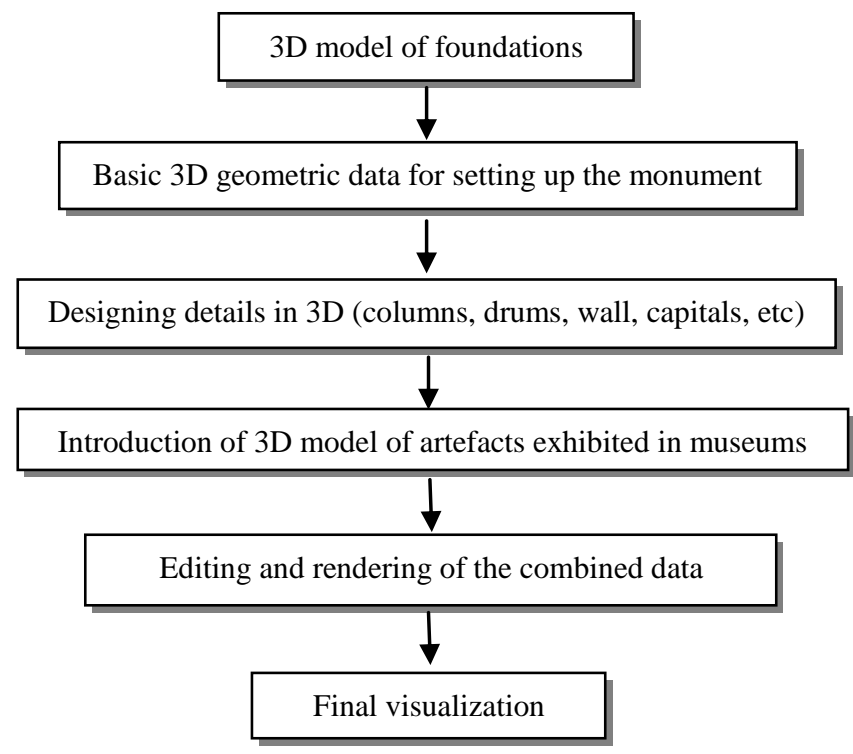

\subsection{D model of the foundations}

The creation of the 3D model of the foundations was performed for a previous project (Karageorgou et al. 2008). The object was scanned with a ToF laser scanner and vertical overlapping high resolution digital images were taken using a special tripod from approximately $7 \mathrm{~m}$ height. In addition numerous GCP's were pre-marked and surveyed in a local reference system.
The point clouds acquired were registered into one, which was georeferenced in the local system. In cases where the scanner failed to measure points, densification of the point cloud was achieved using digital photogrammetric methodology. The point cloud was processed within Geomagic Studio v10 in order to create the 3D model without texture (Figure 4).

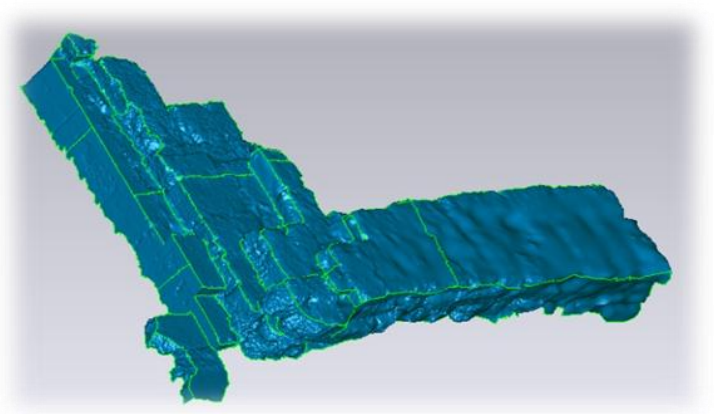

Figure 4: The 3D model of the foundations

Carefully selected digital images were then oriented and draped over the scanned model in order to produce the $3 \mathrm{D}$ textured model of the foundations (Figure 5).

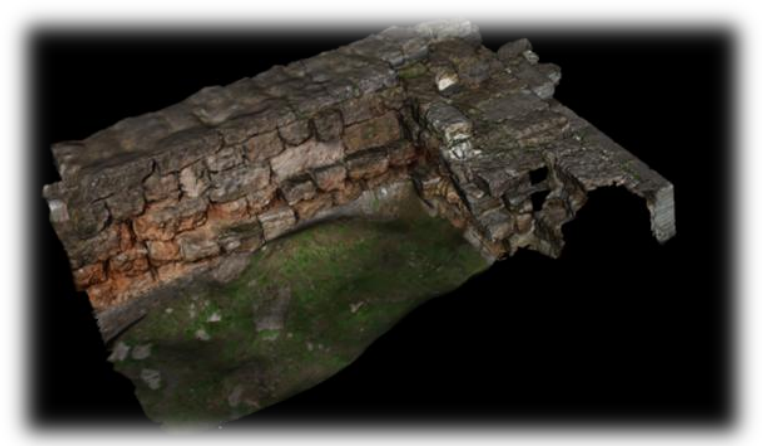

Figure 5: The 3D textured model of the foundations

\subsection{D model of museum artefacts}

For the production of the 3D models of museum artefacts which are still in a good condition, the 123D Catch web service by Autodesk was used. Suitable digital images (Figure 6a) were taken in the museum and they were later used for the automatic creation of the 3D model, which in general does not require any major intervention from the user. The user is required to clear the initial output (Figure $6 \mathrm{~b}$ ) for the production of the final 3D model (Figure 6c).

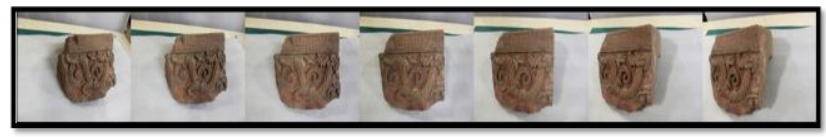

(a)

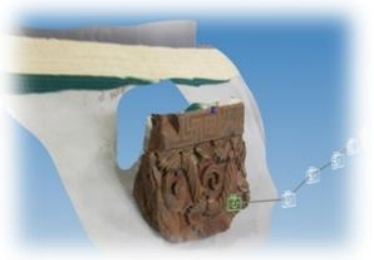

(b)

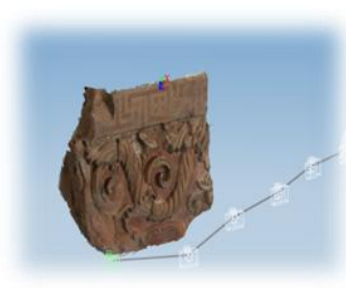

(c)
Figure 6: Creation of the final 3D model (c) of a museum artifact 
This process was used for the creation of the sima (Figure 6), the lion heads serving as gutters (Figure 7) and the ornamental corner tiles (acroteria) or terracotta antefixes (Figure 8).

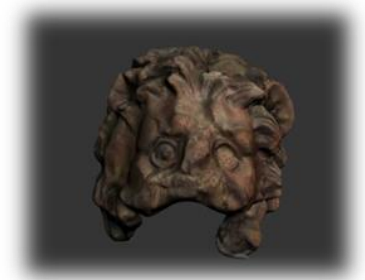

Figure 7: 3D model of lion's head spout

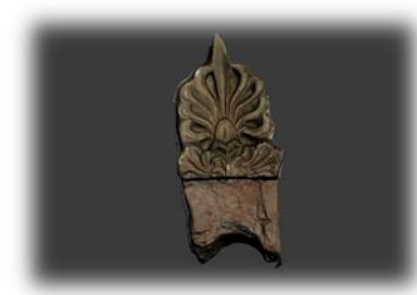

Figure 8: 3D model of terracotta antefix

\subsection{Editing of the data}

First of all the position of the krepis was accurately determined. Its layout, size and position and especially its height relative to the existing foundations were determined using simple surveying measurements. In this way the exact position of the euthynteria was determined, while the exact height level was extracted from a detailed drawing, which illustrated both the foundations and the main building.

The 3D scanned model of the foundations was inserted into 3dsMax (Figure 9). An intermediary level was designed between the Krepis and the foundations, which served to represent the ground level of the initial construction. The main building was constructed above that. The formation of the Krepis, followed its original construction, with slabs positioned carefully in a manner that each slab was resting on two underlying ones, so that the vertical joints did not coincide (Figure 10).

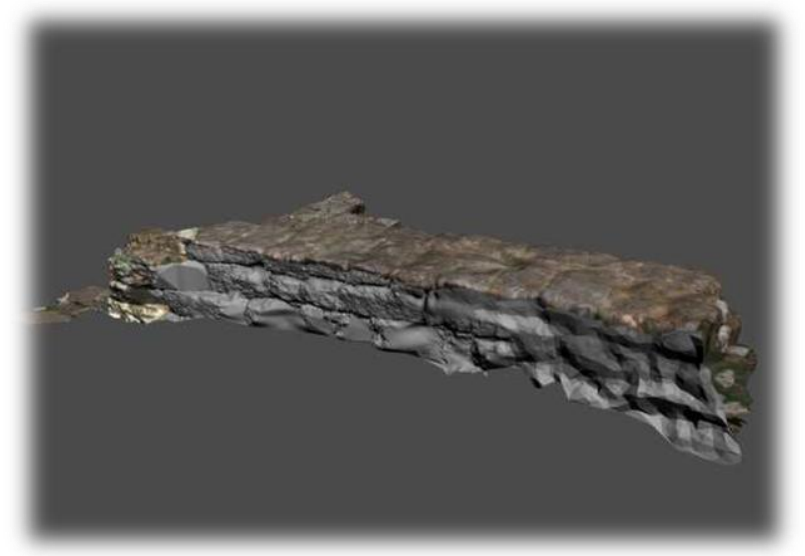

Figure 9: South side of foundation with no texture

Similarly the colonnade consists of the individual columns. Each column consists of conical shaped drums. Their exact dimensions were taken from the detailed reconstruction drawings available (Travlos, 1971). The different base and top diameters and also the slightly varying heights of the drums gave the truthful impression to all final columns (Figure 11).

Between the columns was a low wall joining them, called parapet. This parapet, whose height is not certain, was designed according to the same drawings (Travlos 1971). The top part of this parapet was digitized from the above drawing and the rest was designed according to the dimensions of the individual parts.

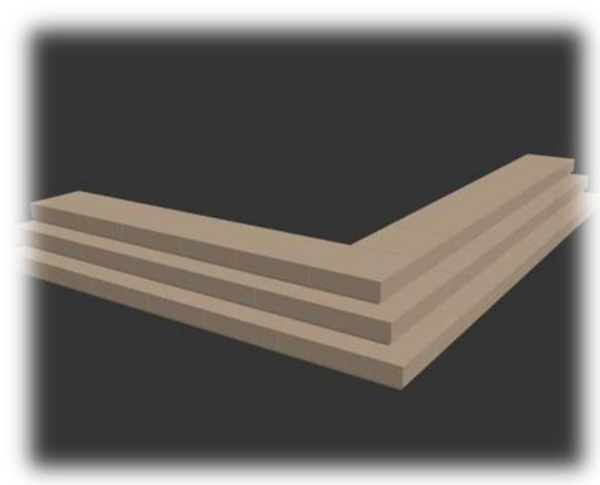

Figure 10: The krepis of Middle Stoa

On top of the Doric columns the echinus and abacus were added as a conical surface and a parallelepiped respectively. For the entablature several considerations were required. The parts forming this section of a Doric order building are the architrave, the frieze and the cornice. The construction of the architrave was based on the available drawings and on the general knowledge of how this part was constructed at the specific era.

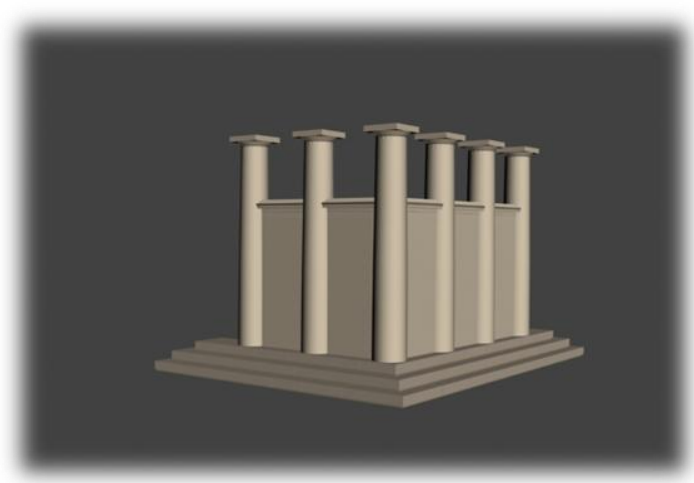

Figure 11: Colonnade with its parapet

At the upper part of the architrave the regulas were added with the guttae underneath (Figure 12). These were ornamental features of ancient Greek building simulating the drops of rain. Their placement was such that each regula was exactly centred above each column, while the very first one on each side of the building was put at the edge of the architrave.

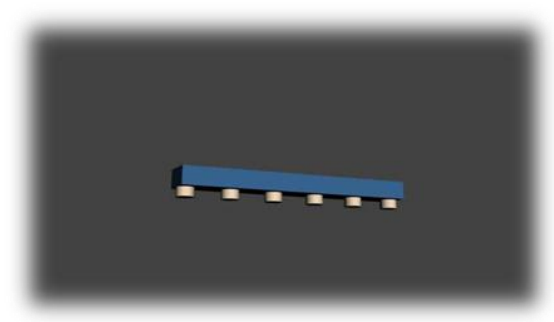

Figure 12: Regula with its guttae

The frieze was subsequently added above the architrave. The frieze in Doric buildings consists of alternating triglyphs and usually empty spaces, called metopes. Depending on the construction era the triglyphs presented different horizontal sections. The proper horizontal section was chosen to correspond to the $2^{\text {nd }} \mathrm{c}$. BC constructions according to Travlos 
(1971), namely with a tri-trapezoidal form of the glyphs or channels. The triglyphs are placed exactly above the regulas (Figure 13).

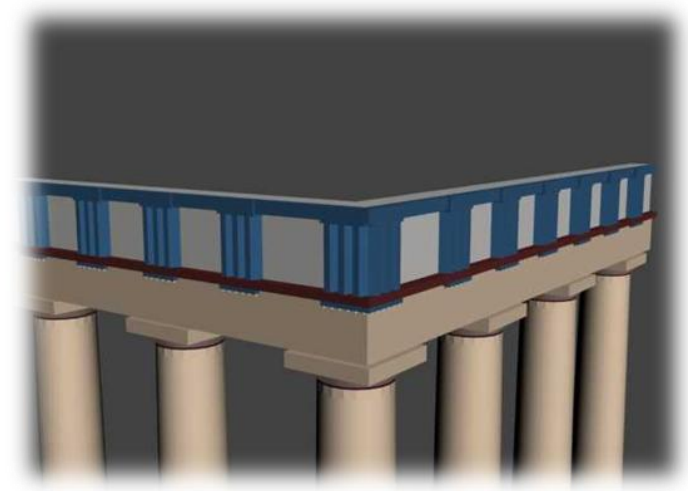

Figure 13: Position of mutules and triglyphs

Above the frieze, the cornice is situated. This part consists of the geison, the raking geison, the sima and the raking sima. The geison of the large side of the building was digitized from an existing drawing. It was inserted into $3 \mathrm{dsMax}$ where it was given the appropriate third dimension and scale and put into the correct place. On this larger side the geison serves also for the runoff of rainwater. The geison of the small side is different and has a different function. It was digitized from drawings of the reconstruction study of the American School of Classical Studies in Athens. Underneath the geison of the large side of the building rectangular plates, called mutules, are positioned ornamented with 18 guttae each. Their design in the 3dsMax software was realized according to Travlos (1971). Their positions were interpreted to be in line with the triglyphs, but also between them (Figure 14). A part of the geison was decorated with Doric waves which are designed according to Muller-Wiener (1993)

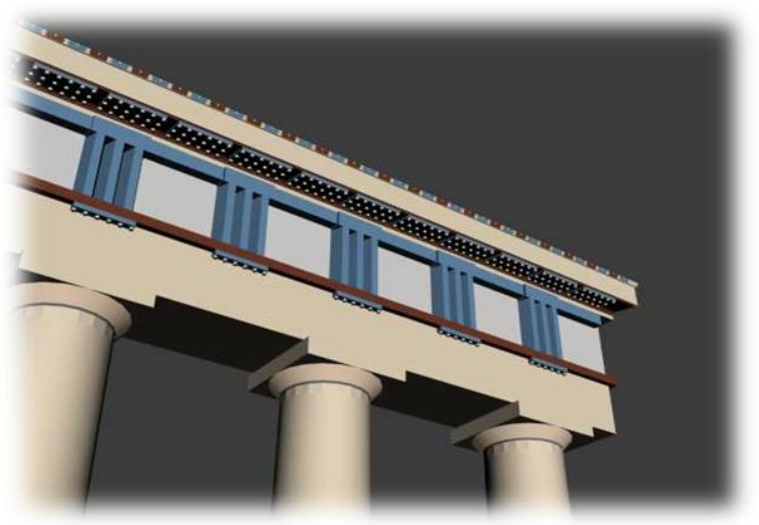

Figure 14: Geison with mutules and guttae

For the reconstruction of the sima various pieces of information were used in combination. From the reconstruction study of the American School of Classical Studies in Athens the sima's level was digitized and imported into 3dsMax. In the reconstruction study by Travlos (1971) it is evident that the sima was decorated with artefacts, such as the lion's head spouts and the acroteria or antefixes. Their 3D models were already created by 123D Catch. These artefacts were also imported into 3dsMax were scaled properly and finally joined together with the rest of the sima's parts to result to its final form (Figure 15).

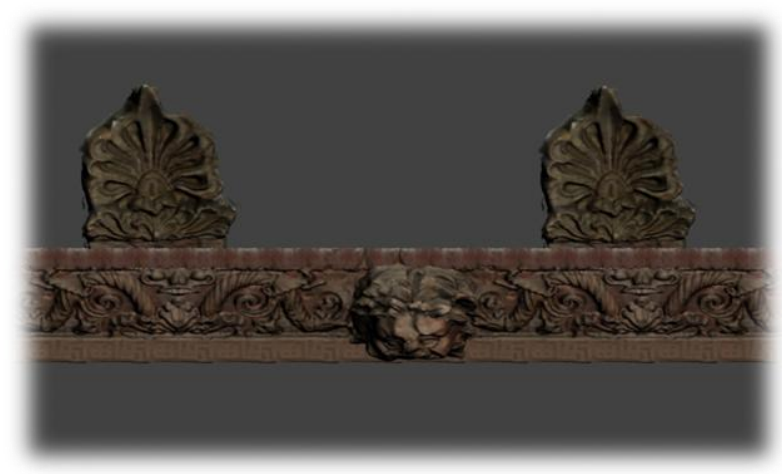

Figure 15: Final form of the sima

At the top edge of the sima, there is a decorative band which is also illustrated in Figure 6. From an image taken for the 3D model of the artefacts, this decoration was digitized and applied on the reconstructed model (Figure 16).

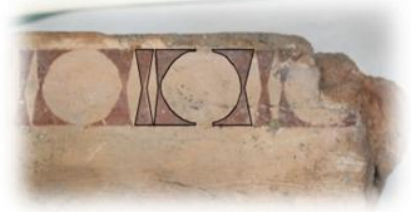

(a)

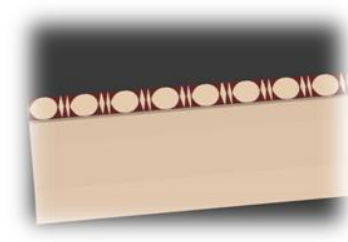

(b)
Figure 16: Decoration of the sima. On an image (a) and in the 3ds Max model (b)

The pediment of the Middle Stoa, i.e. the triangular part of the cornice at the small side of the building was designed based on a drawing which illustrates the reconstructed part of the small side of the building. The first object which was reconstructed was the drum of the pediment which has a triangular shape. Above it the raking geison was positioned, whose section was digitized from the same drawing. On top of that the raking sima was finally positioned (Figure 17). The shape of that part is similar to the sima on the large side of the building. The two simas were joined at the corner of the building with the help of ProBoolean algebra operations provided by suitable commands of the software used.

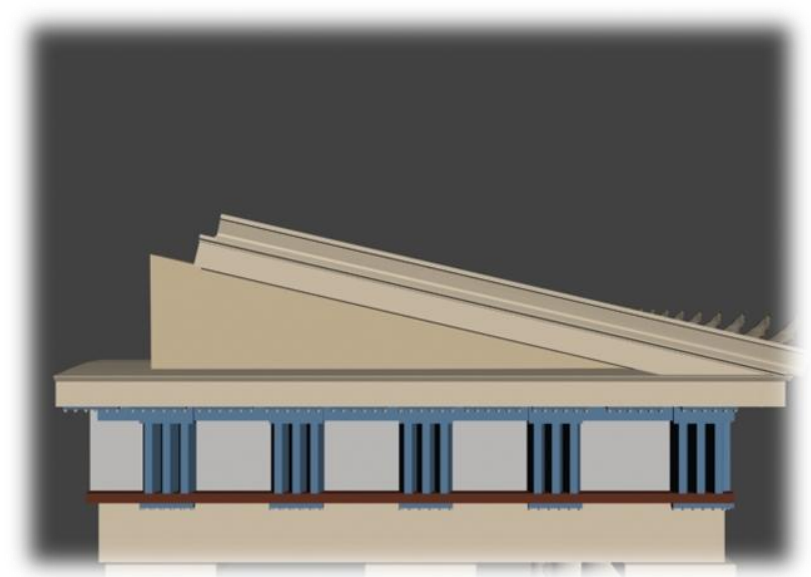

Figure 17: Pediment of Middle Stoa

The inclined roof of the Middle Stoa was, of course, covered with ceramic tiles. For their type there are several assumptions; the most probable one is that they were of Corinthian type and they were placed in such a way that a sleeper tile was 
alternating with an integumentary tile. The sleeper tiles enable the rainwater to flow and, hence, they were positioned exactly behind the lion's head spout. At the end of each integumentary tile row a terracotta antefix was placed (Figure 18).

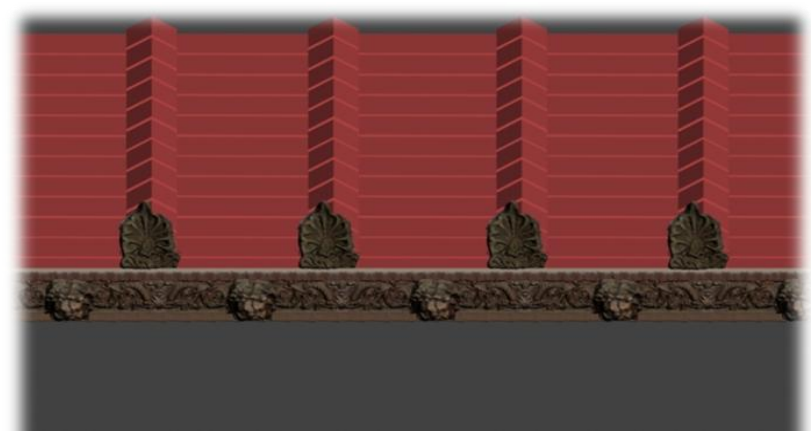

Figure 18: Roof tiling of the Middle Stoa

\subsection{Visualization of the Middle Stoa}

The Middle Stoa, as most of the important buildings of that era, was decorated with colours mainly in the architrave and the frieze. The colouring of the Middle Stoa was performed simultaneously with the phase of the reconstruction. For applying the correct colours, as truthfully as possible, the only available colour depiction (Figure 19) was inserted in a digital image processing software and the digital value of each different colour was carefully determined. Subsequently this value was selected from the 3dsMax colour palette (Figure 20) in order to colour the specified object.

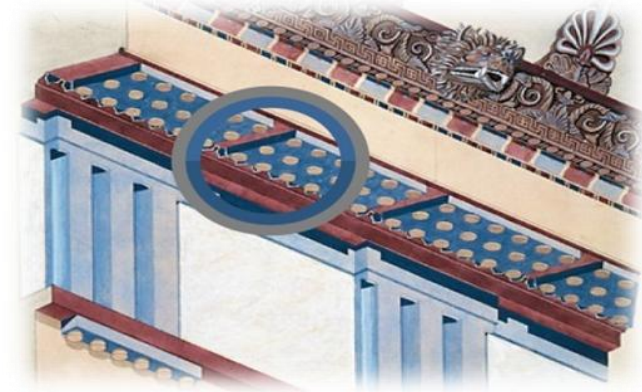

Figure 19: Selected object for its color
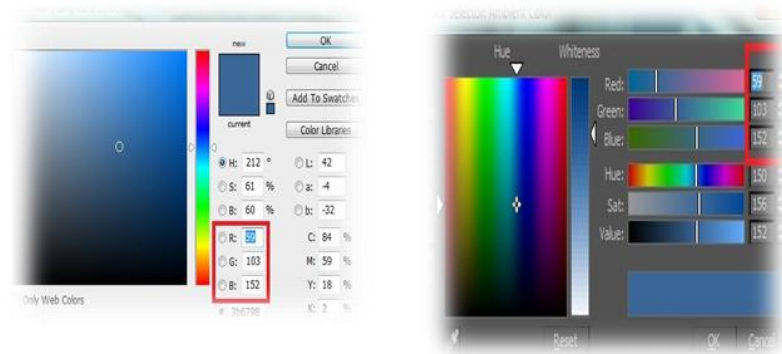

Figure 20: Colour in Photoshop (left) and in 3ds Max (right)

\subsection{Evaluation of the final Results}

In Figures 21, 22 and 23 some views of the final virtually reconstructed building are shown. This final result is as truthful and as accurate as the available information allowed it to be. In certain parts there is no doubt about the initial form. In others various assumptions had been made by historians and architects in the past. For the virtual reconstruction the most probable was chosen, after careful thought and discussion with scientists of related disciplines with deep knowledge of the building.

Such an example is the roof form and tiling, as there was no information at all relative to this subject. The solution adopted is based on how similar and contemporary buildings were constructed. The same holds for the horizontal section of the triglyphs as already mentioned. Although some triglyphs were found during the excavations, they were in such a bad state, that it was impossible to draw firm conclusions as to their form and shape. Similarly the height of the parapet wall is not definitely determined.

For each final decision the verisimilitude table (Table 1) was always a guide. Hence the virtual reconstruction produced could be considered as close to the original form of the building as possible for its state at the 2 nd c. BC.

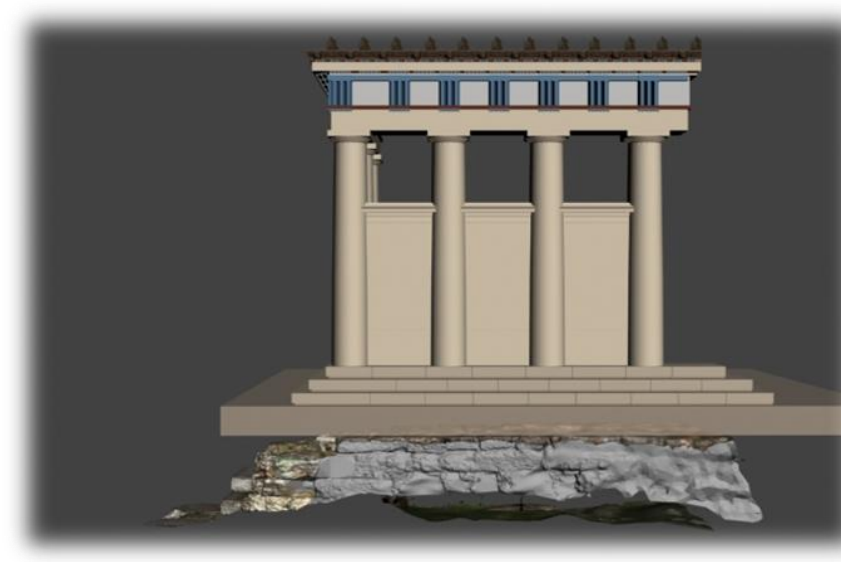

Figure 21: South side of Middle Stoa

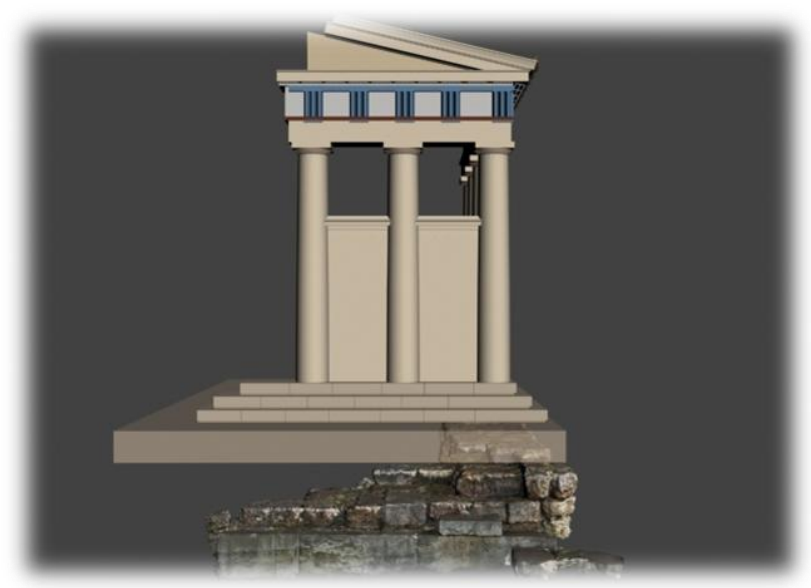

Figure 22: West side of Middle Stoa

\section{CONCLUDING REMARKS}

This final product reconstructs a building that does not exist today. The visitor may only see the foundations of the building, which at the time of its peak $\left(2^{\text {nd }} \mathrm{c}\right.$. BC) were buried in the ground. Consequently the virtual reconstruction is a combination of existing detailed architectural drawings, of sketches, descriptions, digitization of real artefacts and other minor sources of information. Of utmost importance were the discussions and suggestions of scientists who have studied the 
monument from an historical and archaeological point of view, proving once again that a reconstruction is a multi disciplinary process.

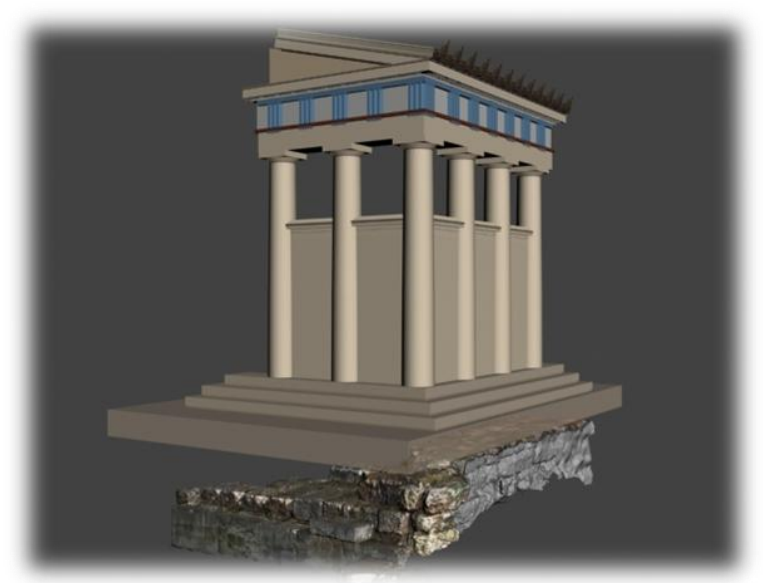

Figure 23: Perspective view of Middle Stoa

Virtual reconstructions have the undeniable advantage that they do not harm the existing architectural elements and, most importantly, they may be reproduced in many different ways depicting each time a different solution to the inevitable questions that arise during a reconstruction process. Thus they could be a very powerful tool for in depth studies of our Cultural Heritage.

\section{REFERENCES}

De Fuentes F. A., Valle Melon J.M., Rodriguez Miranda A. 2010. Model of sources: a proposal for the hierarchy, merging strategy and representation of the information sources in virtual models of historical buildings. CAA conference Proceedings, "Computer Applications and Quantitative Methods in Archaeology", Granada.

Gkintzou, Ch., Georgopoulos, A., Valle Melon J.M., Rodriguez Miranda A., 2012. Virtual restoration of the Ancient State of a Ruined Church. In M. Ioannides et al. (Eds.): EuroMed 2012, Springer Verlag LNCS 7616, pp. 551-567.

KarageorgouM., Barakou A., Briana D., Siora E., 2008. 3D model of the southwestern corner of the Middle Stoa in the Athens Agora. Large Scale Surveys student project, MSc in Geoinformatics, School of R\&S Engineering, NTUA (in Greek).

Lentini D., 2009. The funeral area in "Ponte Della Lama Canosa" (III-VI century) an hypothesis of 3D historicalmonumental reconstruction, Proceedings of 3DArch, Trento, Italy, February 25-28.

Mc Camp II, J., 2004. The Athenian Agora. Excavation in the heart of classical Athens. Translated into Greek, Educational Institute of the National bank of Greece. ISBN 9602502673. pp.287.

Matini M.R., Einifar A., Kitamoto A., Ono K., 2009. Digital reconstruction based on analytic interpretation of relics: case study of Bam citadel. XXII International Symposium of CIPA, Kyoto, Japan. October 11-15.

Muller-Wiener E., 1995. The Architecture in Ancient Greece. University Studio Press, ISBN 9601204849, pp.247 Thessaloniki (in Greek).

Patay-Horvath. 2011. The complete virtual 3D reconstruction of the east pediment of the temple of Zeus at Olympia. Proceedings of 3DArch, Trento, Italy, March 2-4.

Rizvic S., Sadzak A., Ramic - Brkic B., Hulusic V. 2011. Virtual museums and their public perception in Bosnia and Herzegovina. Proceedings of 3DArch, Trento, Italy, March 2-4.

Travlos J., 1971. Pictorial dictionary of Ancient Athens, Thames \& Hudson, ISBN 0500050120, pp. 590, London.

Valle Melon J.M., Lopetegi Galarraga A., Rodriguez Miranda A. 2005. Problems when generating virtual models representing real objects: Hondarribia walls. Proceedings of Virtual Retrospect, Biarritz, France. November 2-10.

www.agathe.gr The American School of Classical Studies website for the Athenian Agora (last visited 31.01.2013) 